\title{
VIOLÊNCIA, SOFRIMENTO SOCIAL E A SAÚDE PÚBLICA
}

\author{
Rubens de Camargo Ferreira Adorno ${ }^{1}$
}

\section{RESUMO}

Trazemos aqui nesse ensaio algumas inquietações acerca do tema da violência e modos de interpretá-la na sociedade contemporânea. Buscando relacionar questões globais, nacionais e locais; chamamos atenção para o que cientistas sociais hoje, particularmente na análise das práticas de saúde, entendidas como um sistema perito vem respondendo a demandas que envolvem uma violência estrutural contemporânea cujo efeito é a produção do que vem sendo chamado de "sofrimento social".

PALAVRAS-CHAVE: Violência, Sociedade Contemporânea, Saúde Pública, Sofrimento Social

Tratar do tema da violência é um empreendimento bastante difícil e complexo em função do intenso destaque que esse tema tem suscitado, tanto na mídia como no debate acadêmico.

Em torno dessa polissemia - de várias vozes, de vários aspectos e de uma grande quantidade de interlocutores - tentaremos aqui reproduzir algumas reflexões sobre a violência na sociedade brasileira, e chamar atenção para uma tematização da violência como um processo cotidiano presente na sociedade contemporânea. Trata-se da reflexão em torno da noção de "sofrimento social", como um sintoma disseminado e que vem sendo entendido como uma forma específica de violência.

\footnotetext{
${ }^{1}$ Bacharel em Ciências Sociais, Doutor e Livre Docente em Saúde Pública, Professor Associado da Faculdade de Saúde Pública da USP e pesquisador do LIESP - Laboratório Interdisciplinar de Estudos Sociais em Saúde Pública. 
Como aspecto central na noção de sofrimento social encontra-se a idéia de que o atual modo de vida social, orquestrado a partir da ação das forças econômicas, sociais, políticas têm tido repercussão sobre os diferentes grupos/classes/identidades das populações.

Essas forças sociais que têm origem na ação de grandes corporações econômicas e na fluidez e total liberdade dos desvarios financeiros internacionais também têm sua contrapartida nas instituições médico, jurídico políticas e policiais, encarnadas pelo Estado, na sua intervenção cotidiana nos diferentes espaços geográficos e sociais.

Estamos diante de fatos paradoxais: como chamou atenção o historiador Eric Hobsbawn, o século XX, tido como um século de profundas transformações e desenvolvimento econômico e tecnológico foi o que mais devastou a vida das populações através das guerras e das práticas de extermínio (HOBSBAWN,1994).

A esse cenário da sociedade mundial, que no plano teórico vem sendo chamada de "contemporaneidade", "modernidade tardia", "capitalismo tardio", chamando atenção para as características sociais, estruturais e econômicos da realidade e suas conseqüências para o cotidiano. Há alguns anos atrás, presenciávamos o termo "pós-modernidade" para aqueles que faziam uma leitura sobretudo a partir dos aspectos “culturais" e estéticos e que falavam de uma nova "época”. Não é nosso objetivo aqui retomar essa discussão, mas de algum modo, concordamos que o perfil das sociedades humanas a partir das últimas décadas do século $\mathrm{XX}$, sofre mudanças que envolvem aspectos profundos na vida das pessoas. Essas mudanças tem tido impacto inclusive na discussão a respeito do próprio modelo de "ciência" e de conhecimento em função de sua maneira de olhar para os seus sujeitos e objetos e a sua relação com a sociedade (ADORNO, 1994). 
Quando tratamos do tema da violência é incontestável que necessitamos lidar com a questão das mudanças na esfera da sociedade. O que seja talvez o aspecto mais relevante diga respeito às relações entre os processos sociais e econômicos que se dão de forma mundial (ou global) e seus efeitos nas realidades locais e nacionais. De que maneira padrões morais, formas de organização de vida, maneiras de adquirir bens para subsistência e existência, modos de sentir e expressar vínculos, sentimentos, emoções acabam sendo afetados pelas transformações de ordem geral.

Uma das perspectivas teóricas, no plano sociológico, para tratar dessas conseqüências globais em relação a aspectos locais foi proposta por Giddens (1991) que afirmava:

Os modos de vida produzidos pela modernidade nos desvencilharam de todos os tipos tradicionais de ordem social, de uma maneira que não tem precedentes. Tanto em sua extensionalidade quanto em sua intensionalidade, as transformações envolvidas na modernidade são mais profundas que a maioria dos tipos de mudança característicos de períodos precedentes. Sobre o plano extensional, elas serviram para estabelecer formas de interconexão social que cobrem o globo; em termos intensionais, elas vieram a alterar algumas das mais íntimas e pessoais características de nossa existência cotidiana (GIDDENS, 1991, p. 14).

Utilizando-se do termo modernidade que remete a uma discussão clássica levantada por Weber sobre a racionalização e a ocidentalização do mundo, Giddens passou a, no plano sociológico, a interpretar essas mudanças no plano do cotidiano. Chama a atenção para o termo "cotidiano", que também passaria a ser valorizado desde as últimas décadas do século passado pelas ciências sociais. A valorização do que ocorre no cotidiano e a intensidade das mudanças são aspectos centrais para esse enfoque. 
Entre os temas tratados por Giddens destaca-se a própria tematização da violência, que seria tratada como a violência "pós-tradicional". Na esfera cotidiana, a partir da observação histórica das sociedades, como menciona, haveria quatro "possibilidades" ou formas de resolver conflitos, "o enraizamento na tradição, o alheamento hostil do outro, o discurso ou o diálogo, e a coerção ou violência” (GIDDENS, 1997, p. 128). A expectativa das sociedades contemporâneas é predominantemente a via da racionalização, que se confronta com as estruturas tradicionais. Como exemplo, o princípio da autonomia dos sujeitos e a conquista das igualdades jurídica, políticas e civis $\mathrm{X}$ a tradição de subordinação de gênero, nas quais as mulheres apesar de trabalharem passam a ser subordinadas aos homens - maridos e companheiros na vida privada.

Essa situação considerada um "desencaixe" da "modernidade", significa que, embora haja um reconhecimento formal da igualdade de direitos no plano "moderno", as relações continuam se pautando pelos princípios tradicionais, qual seja em lugar do uso da linguagem como um mediador de conflitos íntimos, lança-se mão da coerção e da violência física.

Como o núcleo irradiador das "racionalidades" a modernidade viu crescer o papel dos "sistemas peritos", que significam a formação de grupos, instituições, que baseados no conhecimento técnico-científico e principalmente em nome desses, passam a ter competência para tratar tanto das questões técnicas como das questões de conduta nas sociedades.

Assim caberia aos advogados e ao sistema jurídico definir e saber sobre a justiça, aos médicos saber sobre a saúde, ou seja, a partir do momento em que os sistemas peritos definem, a sociedade passa a creditar ou ter "confiança" nessas condutas por eles preconizadas. Assim quando evocados problemas que dizem respeito 
à justiça, à medicina ou à economia, na fala dos peritos, significa uma fala de poder, o que não se deve discutir nem questionar.

A partir dos "sistemas peritos", dos quais fazem parte também os cientistas e a produção científica, os conhecimentos, as condutas etc..., seriam passadas para o grande público através da imprensa, diríamos hoje da internet etc.. Originalmente o autor trabalha com a chamada "literatura de auto-ajuda" ou manuais que são publicados sobre assuntos especializados e voltados para o grande público. A essa projeção do conhecimento técnico-científico e sua apropriação a partir das experiências cotidianas, Giddens chama de "reflexividade" social. Assim, por exemplo, a fala de pedagogos ou psicólogos sobre como se comportar em relação à educação das crianças, ou sobre a violência doméstica é divulgada pela imprensa e incorporada ao cotidiano das pessoas.

O que nos chama atenção e complexifica a situação é o fato de o próprio tema da violência participar da reflexividade social, e nesse sentido identificamos, pelo menos de maneira mais geral, duas questões: as discussões voltadas a tipos específicos de violência, em particular a violência doméstica ou a violência contra a mulher, que vem sendo incorporados ao campo da saúde, e a própria espetacularização da violência que preenche todos os noticiários em torno da divulgação de fatos ligados aos assassinatos que acabam envolvendo a mobilização do grande público.

A discussão em torno desse aspecto não tem um consenso definido, vemos desde os aspectos assinalados por Kleimann (2000) quando cita o exemplo da veiculação de imagens que evocam cenas violentas e que causariam um efeito cotidiano na direção do que poderíamos interpretar como a banalização da violência. Ao entrar em contato com imagens que evocam o sofrimento humano acabaríamos, nas palavras desse autor, por nos tornarmos testemunhas a distância daquele fato, através de uma imagem que representa a ausência do presente ou da presentificação de um fato ausente. 
Como principal efeito dessa exposição cotidiana a imagens que evocam o sofrimento humano ou grandes violências estaria a "naturalização" ou a “essencialização da violência”, a medida que aspectos da nossa emoção passam a ser mobilizados ou negados, pois podemos simplesmente mudar o canal da televisão e decidirmos ignorar aquela cena. Nesse caso preside a idéia da não reflexão sobre os fatos, pois a imagem nem sempre se presta ao entendimento dos contextos, da história.

A filósofa Hannah Arendt, que muito teorizou sobre o tema da violência, chamaria atenção em seu último trabalho publicado para a ausência da reflexão, como uma questão central das relações sociais, políticas e da própria ciência no mundo contemporâneo. A própria ciência, ou o próprio conhecimento que se faz hoje tem como uma (falta) de qualidade a ausência da reflexão como um ato histórico e filosófico que fez parte da história do pensamento no ocidente (ARENDT, 2008).

Estudos sobre violência e mídia, também tem se preocupado com a exposição de crianças e jovens aos meios de comunicação, pois como o processo de acesso e maior consumo de imagens se acelera no capitalismo tardio. A preocupação passa a ser o efeito que essa situação - a exposição cotidiana ao tema da violência na mídia - tenha no futuro, com a passagem da geração jovem à condição adulta.

Nesse sentido Njaine e Minayo (2004) ao realizarem uma revisão sobre violência e mídia, com a preocupação de discuti-las no campo da saúde pública, destacam o fato de:

[...] As imagens estereotipadas de grupos sociais como mulheres, homossexuais, negros são abusadamente utilizadas pela mídia e se constituem em uma forma de violência pouco reconhecida pela sociedade e por vezes é motivo de diversão e sarcasmo. Mas é importante também lembrar que os níveis de violência na vida real muitas vezes não são sempre reconhecidos e que a discriminação e o preconceito, por exemplo, não são Revista Serviço Social \& Saúde. UNICAMP Campinas, v. IX, n. 9, Jul. 2010 
atitudes exclusivas dos profissionais da mídia, estando presente também nas práticas dos profissionais da área da educação e da saúde que lidam com crianças e adolescentes refletindo negativamente na socialização desse grupo [...] (NJAIME, MINAYO, 2004, p. 209).

Ou seja, ao pensar na mídia temos que relacionar os sentidos que são construídos na vida real perante os fatos, e que acabam por dialogar de maneira a serem reforçados e trabalhados reflexivamente pela mídia.

Chama-nos atenção na citação acima o fato de o processo social de construção de um determinado sentido para determinados fenômenos atravessar a construção de determinados momentos históricos de dada sociedade, e que mais do que o fato em si, qualifica de maneira estereotipada seus agentes. Assim nas sociedades contemporâneas assistimos a atribuição do sentido da violência ao outro: seja o migrante, o imigrante, o que não pertence a minha classe social, o que presumivelmente não tem o meu comportamento.

Dessa forma ao refletir no plano genérico o sentido da violência acabamos por, antes de procurar conhecer os fatos, atribuir à violência a imagem do outro.

Essa questão passa a ser mediada pelas reações da sociedade contemporânea à própria violência, e aos programas "institucionalizados" que procuram responder a fenômenos específicos da "violência", como a violência doméstica, a violência sexual, a violência contra mulheres, crianças, adolescentes e jovens.

Creio que podemos identificar nessa exposição sobre a violência e a sociedade contemporânea a existência de um dispositivo, dirigido ao sujeito e a governamentalidade, como apresenta Rabinow (1999) essa idéia de Michel Foucault. A sociedade contemporânea ao mesmo tempo em que reflete, repudia e cria mecanismos de controle da violência que se voltam para o que seria um "cuidado se si" do sujeito, ou 
uma disposição a pacificação e racionalização de seus atos, acaba por encenar essa temática e colocá-la como um tema que atrai atenção, desejos, sentimentos, emoções.

A mídia também acaba, em suas espetacularizações, buscando um reforço ou uma explicação para acontecimentos complexos como a violência em sistemas peritos, que muitas vezes tratam de forma a restringir ações que estão arraigadas no social, nas relações sociais e nas estruturas da sociedade, para serem explicadas ou solucionadas através de uma razão técnica, que em geral a localiza no sujeito. Se antes havia uma explicação fenotípica, hoje olha-se para dentro dos sujeitos para dizer que lá há algum índice que explique sua ação.

A própria área de saúde como normatizadora de ações técnicas em relação aos indivíduos acaba por incorporar o tema desse dispositivo, seja como torná-la uma ação técnica, seja para refleti-la criticamente e pensar ações coletivas na direção de discussão social desse dispositivo da violência/pacificação.

\section{DESENVOLVENDO A DISCUSSÃO NA SOCIEDADE BRASILEIRA}

Em um editorial especial de um número temático sobre violência, Sergio Adorno (2008) ao situar a violência como forma de resolução de conflitos tanto nas relações sociais mais amplas como nas relações interpessoais, registra que sua inscrição na sociedade brasileira, como uma herança colonial, traz a tona a memória da brutalidade e crueldade que dessa época histórica persistirá no período imperial e republicano, qualificando-se na contemporaneidade seja no âmbito privado, seja a partir das instituições sociais, seja a partir de modelos de masculinidade que a colocam como preceito moral entre jovens do sexo masculino, destaca como um ponto importante as iniciativas de pensar essa questão na academia e nas políticas de controle social e legal. 
Se de certa forma definimos na sociedade brasileira uma questão histórica que apresenta a reprodução da violência como maneira de solucionar desde questões banais e cotidianas até a demonstração de valores sociais de poder, tanto nas instituições, na hierarquia social, como nas questões de gênero, esse corolário se complexifica em relação a contemporaneidade, que em grande medida acelera o tempo e as relações entre conflitos locais, estruturais e as mudanças globais.

Caldeira (2000) introduz o seu livro "Cidades de Muros", sobre a cidade de São Paulo, destaca a "violência e o medo" (p. 9) como participantes das mudanças das cidades contemporâneas, e tendo como efeitos a intensificação dos processos de segregação espacial e discriminação social, segue-se a esse processo a intensificação dos próprios discursos sobre o "medo" relacionado ao crime e ao "crime violento" incorporados a aspectos étnicos e raciais, "preconceitos de classe e referências negativas aos pobres e marginalizados” (p. 9). Discursos do medo e práticas de segregação representam fórmulas como as elites do mundo vêm resolvendo a configuração das cidades.

Interessante a pesquisa realizada pela autora que persegue a intensificação dos discursos sobre a violência, a impunidade, a sua representação na mídia e o período de democratização do país após a ditadura militar. Demonstra que as instituições democráticas não conseguiram resolver a questões atinentes a própria cidadania no cotidiano, ou romper com a desigualdade social e os impedimentos da generalização da cidadania.

Por sua vez o discurso do crime e do medo, presentes na ditadura militar transfiguram-se no discurso de emissoras de rádio e de televisão que focalizando os crimes criam no imaginário da população a idéia constante de um "inimigo" ou "criminoso" que estaria, a todo o momento, dispostos a atacar a propriedade e as 
pessoas que estão dentro de suas casas. Esse inimigo aparece no imaginário associado a aparência da população pobre e marginalizada, reiterando uma exclusão social e étnica racial.

Essa situação contemporânea tem levado a evidência o caso de países latino americanos como no caso do Brasil e outros países do MERCOSUL, que teriam vivenciado apenas situações fragmentadas ou inacabadas de um Estado de Bem-Estar Social, que se voltaram a setores dos trabalhadores assalariados e não lograram integrar o conjunto da população e as situações de grande desigualdade social - mais típica do caso brasileiro - e desigualdades regionais.

Nosso entendimento aqui é como relacionar as situações de violência a essas questões estruturais. Dessa primeira questão resulta que ao considerar no Brasil o grande fosso existente entre as camadas sociais altas e médias e as camadas mais pobres da população há que pensar na segregação que passa a existir no contexto urbano em função da discriminação da área de moradia, cor da pele, vestimenta e da "prepotência no tratamento dos considerados inferiores" (DA MATTA, 1990, citado por KOWARICK, 2009). Este mesmo autor cita também O’Donnel, para se referir ao que chamaríamos aqui a experiência cotidiana de vivenciar relações de autoritarismo, discriminação, poder e violência, nas quais os que se sentem em circunstâncias de contato e/ou conflito de ocupação do espaço, com aqueles que julgam "inferiores" na hierarquia social, justificam plenamente apropriar-se de privilégios, em função de sua posição social.

Situação complexa seria desenvolver aqui a questão da "cidadania" que envolve desde a distribuição desigual de bens e recursos, mas também a prática cotidiana de relações sociais entre cidadãos que se autoclassificam como "superiores" ou entre cidadãos discriminados pela cor da pele, origem, local de moradia e 
funcionários do Estado, em serviços de saúde ou outros ou explicitamente no caso da ação policial.

Se reconhecermos uma herança histórica de desigualdade e de violência institucional por parte do Estado na sua relação com as populações mais pobres, na ausência de políticas sociais, na incapacidade da universalização da educação básica. Situação que registra um aspecto do que vem sendo chamada de "violência estrutural", as questões contemporâneas da violência revelam novos aspectos que se intensificam a partir das relações entre questões locais, nacionais e globais.

Um dos aspectos dessa relação diz respeito ao chamado "crime organizado" como uma organização de cunho transnacional, que no Brasil se articulou através do tráfico de drogas - notadamente a da cocaína - estruturando localmente suas bases nas regiões periféricas, como no caso dos morros e favelas do Rio de Janeiro (MISSE, 2006)

De certo modo podemos chamar a esse fenômeno de uma internacionalização da violência no Brasil, que a partir dos anos 70 passa a instalar as bases de um fluxo de bens do mercado paralelo, que de um lado vende cocaína e de outro trafica armas, ou as recebe através da corrupção policial, sustentando um sistema hipócrita e perverso, que de um lado se beneficia de agentes da própria instituição da segurança pública e de outro intensifica a repressão a esse mesmo mercado, estimulando uma guerra absurda que só faz alimentar a indústria de armas e a produção de mortes.

A associação dessa guerra nas regiões periféricas tem como principais envolvidos jovens e pobres, que por sua vez passam a ser apontados na mídia como os “responsáveis" pela violência urbana. Misse (2006) assinala que através do efeito da mídia ocorre uma visão indiscriminada acerca dessa violência, que coloca em um mesmo patamar "crimes passionais, estupros, vinganças pessoais, tráfico e consumo de 
drogas, assaltos a carros forte, seqüestros, furtos [...]” (2006, p. 27). Reforçando a imagem da associação da violência ao mundo dos bairros pobres.

Aspecto a ser destacado é o do envolvimento, sobretudo de homens jovens nessa guerra particular das regiões periféricas que se irradia das grandes para as médias e pequenas cidades brasileiras. Esse fato também serve para registrar a relação entre os efeitos globais da circulação de atividades de uma economia paralela global em redes locais. Devemos considerar a ausência de espaços das periferias da cidade, não apenas de lazer, mas de locais nos quais os jovens possam encontrar "canais" de participação, ou "canais" para que possam sair do anonimato.

Autores como Zaluar (2010), consideram o individualismo como um dos traços contemporâneos. A combinação entre o "ethos" individualista contemporâneo e as características de uma "masculinidade" tradicional, encontra na atividade paralela um espaço de agenciamento.

Homens jovens que participando direta ou indiretamente das atividades de tráfico, passam a ter fácil acesso a armas de fogo, e a partir daí a usam tanto na "guerra particular", ${ }^{, 2}$ como para resolução de conflitos pessoais.

Em uma pesquisa que realizamos há alguns anos no município de São José dos Campos, entrevistando famílias de jovens autores e vítimas de homicídios, encontramos o relato de histórias que aparentemente banais representavam a expressão pública do que se considerariam ideais de uma masculinidade tradicional. Um jovem assassinava outro por ter "paquerado" sua namorada, em seguida o irmão ou um primo desse segundo jovem assassinaria o primeiro como vingança ao assassinato que praticara.

\footnotetext{
${ }^{2}$ A expressão "Guerra particular" remete ao documentário de Katia Lund e João Moreira Salles sobre o combate sem trégua entre policiais e traficantes.

Revista Serviço Social \& Saúde. UNICAMP Campinas, v. IX, n. 9, Jul. 2010
} 
Assassinatos que, envolvendo a questão da "honra" masculina se sucediam em redes e em círculos locais, evidenciando o uso da força na resolução de questões cotidianas, o que demonstra também uma determinada mobilização das emoções e das relações de alianças envolvendo tanto aspectos consangüíneos como de afetividades masculinas.

O número de homicídios nas periferias das cidades brasileiras assume uma proporção crescente a partir de meados da década de 1980, tendo como ressonância amplificada a espetacularização da violência da mídia e a construção do "outro", do habitante da região periférica, do pobre como o responsável pela violência. Além da "guerra particular" e dos conflitos pessoais resolvidos por armas de fogo, esse processo de ocupação dos espaços da periferia por essas formas de violência, aliado ao envolvimento de agentes da polícia com as atividades locais e a falta de presença do Estado, particularmente da segurança irá se relacionar com o agenciamento de outras práticas de violência. Desde a contratação de seguranças particulares, a formação de grupos de extermínio. Misse (2006) comenta a situação de que, a pena de morte, passaria a existir no Brasil, mesmo na ilegalidade.

Em uma pesquisa realizada em 2001 com jovens de quatro áreas metropolitanas brasileiras, registramos que em todas elas a violência era apontada pelos jovens como um ritual cotidiano, no qual se banalizava a vida.

Em Recife a menção aos “justiceiros” que passavam encapuçados disparando tiros, impondo o toque de recolher nas periferias e a presença de corpos baleados no caminho de ida para as escolas foram reportados como fatos cotidianos. No Rio de Janeiro o direito de ir e vir obstruído quer pelas forças policiais, quer pelas milícias ou pela polícia cada qual dominando um espaço da área e obrigando a se negociar a passagem. Em São Paulo os jovens, nas entrevistas, falariam das "batidas" policiais 
constantes e da violência com que eram interpelados ao caminhar pelas ruas da periferia, sendo obrigados a encostar em paredes sob a mira de armas para serem revistados, insultados e humilhados.

As chacinas, se parte da história brasileira, passam a ser representativas da história recente: $\mathrm{Acari}^{3}$, Vigário $\mathrm{Geral}^{4}$, Complexo do Alemão ${ }^{5}$, Candelária, São Bernardo, Perus, Carandiru, nomes de origem tupi-guarani e nomes eclesiásticos, marcantes da formação identitária brasileira, mas com seu lado oprimido e negado, massacres que o próprio Estado, se envolve e que a os poderes judiciário, legislativo e executivo se mesclam nos descaminhos de investigação que não se concluem.

De alguma forma mostram uma transversalidade entre a esfera policial e a esfera política. Como indaga Oliveira (1997), a respeito dos "excluídos" na sociedade brasileira, na qual não se trata de tentar caracterizá-los a partir de uma exclusão econômica, mas sobretudo de uma exclusão ética e política. Ou seja, pensar nessa violência estrutural significa interpretá-la a partir de um elemento político que é transversal na estrutura do Estado, e que envolve desde as práticas de policiais até o apoio que recebem no plano legislativo de deputados, e em seguida com peso no setor judiciário e certamente no próprio poder executivo.

É instrutivo lembrar que o "massacre do Carandiru" foi acionado a partir da concordância do próprio governador do Estado de São Paulo, na época. Deve-se

\footnotetext{
${ }^{3}$ A Chacina de Acari ocorreu em 1990, envolvendo o assassinato de onze pessoas, sendo sete menores de dezoito anos, moradoras da favela do Acari no Rio de Janeiro, cujos corpos foram levados para local ignorado e até hoje não encontrados. As mães dos desaparecidos iniciaram uma mobilização pela busca dos filhos e por justiça. $\mathrm{O}$ inquérito aberto até hoje segue sem resultados. As mães sofreram ameaças e uma delas foi morta, supostamente por vingança.

${ }^{4} \mathrm{Em}$ agosto de 1993, cerca de 50 policiais integrantes de um grupo de extermínio conhecido como os "Cavalos Corredores", invadiram a favela de Vigário Geral, no Rio de Janeiro, assassinando 21 pessoas. O comandante desse batalhão se elegeu deputado e desde aí defendido essas ações policiais.

${ }^{5}$ Em maio de 2007, uma operação da polícia no Complexo do Alemão envolvendo mais de mil homens de várias delegacias, deixou um saldo de 19 mortos. Grande parte das vítimas apresentou sinais de tortura e execução
} 
registrar que episódios como esse acabam recebendo apoio de uma parte da opinião pública, que como discutimos atribui a violência ao outro, e não convive com a idéia de um dispositivo pacificador das relações sociais, ou da reciprocidade que envolve as relações sociais.

\section{DA SEGURANÇA À SAÚDE: UMA NOVA GOVERNALIDADE?}

Apesar de ser o espaço das periferias ocupado pela insegurança e pelo medo, preside aí a falta de segurança, seja pela ação de policiais ou policiais a serviço de grupos de extermínio ou outros interesses, seja pela "guerra particular" em função do tráfico de drogas, nos parece que governos locais, estaduais, parecem ter respondido, como estratégia de governabilidade, em função de interesses de outras camadas da população. Apenas mais recentemente tem havido a partir de parcerias com o governo federal alguns esforços de pacificação das polícias ou projetos especiais em determinadas áreas periféricas.

Enquanto política pública, de caráter mais abrangente, no plano nacional registramos a existência do Sistema Único de Saúde (SUS). Como inscrito no documento denominado "Carta 20 anos do SUS" (2010) a sua implantação representou a maior política de inclusão social do Brasil, como um sistema universal, "participativo com controle social" que abrange todo o território nacional. Esse sistema se propõe a trabalhar com o conceito ampliado de saúde, que se dispõe a tratar a "qualidade de vida com promoção, prevenção e atenção (e não somente a doença)".

De fato a grande expansão da atenção médica durante o século $\mathrm{XX}$ e particularmente após a Segunda Guerra Mundial respondeu também a fenômenos que foram denominados de "medicalização da sociedade" (ILLICH,1975; DONNANGELO, 1976 ; SINGER, P et al.,1978), e ao fato de a assistência médica ter sido incorporada 
parcial ou integralmente ao consumo da sociedade através das políticas de Estados modernos passando a fazer parte do Estado do Bem-Estar Social. Respondendo às demandas individuais através do atendimento médico individual, que passa a operar como um mediador entre a população e o consumo médico, basicamente de medicamentos e outros insumos financiada também integral ou parcialmente através do Estado. Assim sendo os serviços de saúde respondem como lugares nos quais se processa o consumo médico que tem atrás de si um complexo financeiro e industrial como o que envolve o setor de medicamentos; e o Estado garante a governabilidade no sentido de encaminhar soluções aos conflitos e problemas a partir de um equipamento de atenção.

Internacionalmente autores como Fassin (1998), tem chamado atenção para as novas conformações que vem tomando a "saúde pública", que em sua história se colocou explicitamente como um campo de intervenção sobre a sociedade ou sobre equipamentos coletivos visando mudanças na saúde da população. Essa questão histórica é por sua vez bastante recorrente nas polêmicas que envolvem as práticas dos profissionais, levando inclusive no Brasil a construção do termo "saúde coletiva" para diferenciar a ação da saúde pública da atenção médica.

No plano geral é quase já do senso comum a idéia de que a saúde de uma população é a expressão de sua qualidade de vida, que é dada pelo modo e pelas condições de vida social e ainda pelo lugar social que ocupa na estrutura da sociedade. No entanto, falar em ações coletivas ou mesmo no discurso da "prevenção" em uma sociedade voltada para o consumo como a sociedade contemporânea é uma questão difícil ou pelo menos não generalizada.

Nesse sentido Fassin (1998) localiza hoje a saúde pública na ação de redes ou empreendimentos locais que mobilizam várias instituições, profissionais, lideranças 
locais em torno de questões e lutas específicas naquele contexto. Questões que se tornam transversais a assistência médica e que envolvem a ações de cunho social, como melhoria de condições de moradia, maior proteção aos idosos ou as crianças, inclusão de populações excluídas e inclusive a atenção para o sofrimento social. Nessa direção mais específica o autor desenvolve ao que chamou de uma configuração semântica da ação pública.

Questões do campo da sociedade como a exclusão, a desigualdade e a violência e suas conseqüências sobre os indivíduos podem ser interpretados como "sofrimento", em grande parte a produção das ciências sociais contemporâneas tem produzido essa noção.

Fassin (2006) chama atenção para o fato de que essa compreensão tenha levado a proposição de seu "tratamento" através do reconhecimento do sofrimento psíquico, em grande parte também em função da sensibilidade de psicólogos e psiquiatras que junto com quadros do Estado na França, passaram a reconhecer a necessidade de uma forma de atenção à saúde mental voltada para a escuta das pessoas "excluídas". Interpreta que ao lado da discussão da "despsiquiatrização" e “despsicologização" como ações necessárias, (no Brasil representado pelo movimento “anti-manicomial”), acabe ocorrendo o contrário: uma psiquiatrização e psicologização do efeito das questões sociais. Assim problemas que se remetem ao político e ao econômico, tratados a partir da "compaixão" e da "repressão", acabem sendo remetidos a uma função reparadora através dos serviços de saúde, especificamente aos serviços de saúde mental.

Nesse processo fala-se de equidade como uma equação técnica a ser promovida pelo serviço que se volte aos que apresentem maiores "vulnerabilidades", deixando de a igualdade ser refletida como um valor ou um ideal a ser perseguido. 
Toma-se questões de natureza distributiva, como os bens econômicos, os direitos sociais, civis, a justiça; para se tratar de uma assistência reparadora.

Essa discussão nos remete a pensar ações que vem sendo encaminhadas também na sociedade brasileira através do SUS, das políticas de saúde mental e da própria incorporação do tema da violência nos serviços de saúde.

Em relação a essa última questão verificamos que vai se incorporar a partir de uma demanda segmentada: mulheres, crianças e adolescentes vítimas de violência, seguindo um modelo prescritivo e programático que compartimenta o corpo e a noção de violência (SARTI, 2009). Também se organiza em relação a uma funcionalidade em consonância com um modelo epidemiológico da violência dentro das causas externas como o caso do atendimento às vítimas de acidentes de trânsito e as redes locais de remoção e atendimento hospitalar; ou a dirige ao consumo de saúde, como a demanda por cirurgias plásticas ou reparadoras realizadas pelo SUS para mulheres vítimas de violência.

Seguindo uma lógica de individualizar e compartimentar demandas dirigindo a tipos específicos de cuidado à saúde, desenha-se a partir de um conceito ampliado de saúde voltado para o bem-estar social, uma lógica de acesso a ações de reparação. Uma lógica que vem de certo modo se adequar ao tema da "medicalização da sociedade" mais candente na discussão dos anos 70 e 80 do século passado, e ao mesmo tempo dirigindo-se a demandas mais sofisticadas de consumo do atual século. A ação política dos serviços de saúde como de reparação compensatória 'as injustiças e desigualdades sociais'.

Se pensarmos na conjunção do universo "psi” a partir das preocupações que Fassin (2006) enuncia para a situação francesa, registramos que essa versão também tem se consumado no território brasileiro a partir da atenção à saúde mental. A 
preocupação daí reside em questões como a interpretação "psiquiátrica" e "psicologizante" da violência, não temos a pretensão de tratar essa discussão nesse espaço, mas destacamos a preocupação desse enfoque quando deixe de participar na interpretação da violência no contexto da sociedade e passe a reforçar o dispositivo que destacamos anteriormente, o da individualização do fenômeno da violência.

De qualquer modo levantar esses aspectos críticos nos leva a uma situação paradoxal, como mais um "desencaixe" da contemporaneidade. Talvez participar da grande política pública brasileira de universalização da saúde articulando os contextos mais amplos de discussão de um tema tão central como a violência na sociedade brasileira.

Como tratar de seus aspectos tradicionais que vem sendo impactados pelo sentido global da contemporaneidade que articula temas como a masculinidade e a violência de gênero e as atividades dos mercados paralelos? De algum modo esse desafio nos leva a articular os problemas no contexto local, buscar parcerias, formas de organizar coletivamente autores e vítimas e demandar por uma concepção mais ampla de política pública que remeta a igualdade frente à justiça, políticas locais mais inteligentes e menos policialescas de segurança.

Para além da atenção reparadora observamos algumas mudanças em cenários locais e ou regionais na situação brasileira, como a queda da taxa de homicídios no Estado de São Paulo, ao lado do recrudescimento da "guerra particular" no Rio de Janeiro também anunciada como a "pacificação" de algumas áreas.

No caso do Estado de São Paulo, enquanto o governo anuncia o fato como fruto da ação policial, outros especialistas na imprensa questionam sobre essa relação de casualidade, argumentando que outros crimes como os crimes contra o patrimônio não estão sofrendo queda, o que levanta dúvidas sobre os argumentos oficiais. 
No caldo dessa discussão continuam ainda hoje os defensores de endurecimento da repressão como forma de diminuir a violência, política que foi sempre defendida pelos que justificavam as ações repressivas do Estado desde o regime militar e que posteriormente passaram a executar essa ação como uma ação de governabilidade, ao receber apoio do eleitorado mais conservador. Nessa mesma direção ocorreriam ações como o "massacre do Carandiru", que desgastava mais uma vez a imagem do país no plano internacional e na direção do dispositivo de pacificação, que busca responder com inclusão e reconhecimento dos direitos.

A política adotada em áreas faveladas da cidade do Rio de Janeiro tem seguido uma preocupação com a dotação de infra-estrutura e melhoria urbana, avaliadas como medidas urbanas de prevenção à violência, ao mesmo tempo são comentadas como possíveis desencadeadoras de uma evasão da população mais pobre das áreas pacificadas.

Da mesma forma em relação ao tráfico de drogas, a política de recrudescimento da repressão tenderia a pulverizar as redes distribuidoras em escala nacional, ou deslocar para outras áreas a distribuição. Em bem menor proporção do que a violência os fenômenos contemporâneos do consumo de drogas tem sido atribuídos ao campo da saúde pública, que em países como a França e grande parte da Europa têm uma política baseada em ações de "redução de danos" em lugar de utilizar a repressão e dessa maneira aumentar a violência social.

Pensar na mudança da política de repressão às drogas, em função do reconhecimento de que existe uma diferença entre uso de uma droga e desenvolvimento de "problemas com o uso", ou seja nem todos os que usam desenvolvem problemas com o uso; em segundo lugar de que o uso na ilegalidade traz mais riscos pessoais, psicológicos e físicos aos usuários do que uma política que discriminalize usos. Assim 
grande parte das drogas distribuídas não passa por um controle e podem conter substâncias mais nocivas do que as próprias drogas para o usuário.

Ao lembrar o tema do uso de drogas e sua relação com um mercado internacional que na ilegalidade relaciona-se com a distribuição nacional e local a partir de meios violentos, como as armas de fogo, importante é também reconhecer o uso das drogas como forma de "medicalização" dos conflitos sociais em serviços de atendimento em saúde mental. Mendonça et al. (2008) mostram como nos serviços de saúde mulheres idosas que sofrem conflitos de gênero ou outros conflitos domésticos são tratadas com antidepressivos.

\section{PENSAR, INVESTIGAR E TRABALHAR COM AS MARGENS}

Das (2008) desenvolve em um texto sobre o lugar das "margens" nos estudos da antropologia na sociedade contemporânea, para identificar como a partir dessas populações não "colonizadas" de forma cabal pelo Estado, pode-se interpretar a sociedade a partir de suas fissuras. Creio que na sociedade brasileira esses exercícios devem ser importantes e estimulados, para admitir a compreensão dos modos de vida e de como eles se relacionam com os poderes de Estado, com a repressão, com o consumo.

Numa situação por vezes extrema como a brasileira, que para além da violência é uma sociedade que convive mesmo que, da maneira que se sabe, episodicamente com práticas de extermínio temos na verdade situações-limite. Nesse sentido a interlocução com textos com os de Veena Das apresentam possibilidades de aprofundar reflexões. Para essa antropóloga existem as violências cotidianas nas quais as vítimas investem no tempo como uma forma de resistirem a opressão, e existem "eventos críticos" que apresentam formas de violência que são testemunhadas mas das 
quais não se falam por extrapolarem os limites do que se considera o humano. Esses eventos críticos encontrarão reações a partir do tempo.

Fatos como as chacinas e as várias agressões e intimidações, massacres etc.. tem levado a organizações de resistência. Nesse sentido trabalhar a partir das margens e do atendimento implicaria em trabalhar com as reações coletivas à violência. Assim os serviços de atenção necessitariam superar a prática insuficiente do atendimento ao indivíduo.

Logicamente o atendimento e a reparação física são incontestavelmente aspectos que uma política de Estado deva responder, mas em si insuficiente. Da mesma forma o tratamento aos autores da violência não ocorre no atual sistema carcerário, que tem se comportado como Wacquant (2001) tem chamado a política de encarceramento, como uma política de encarceramento da pobreza e da exclusão.

Esse autor considera os efeitos da penalidade, como um dispositivo de práticas, instituições e discursos relacionados à pena criminal, ou seja, ao encarceramento, no contexto neoliberal, no qual o Estado, incapaz de controlar a "decomposição do trabalho" e refrear a "hipermobilidade" do capital, que desestabilizam a sociedade como um todo reforça a estratégia policial e de encarceramento das populações pobres.

Para terminar gostaria de citar o trabalho de Biondi (2010) que naquele sentido de compreender aspectos da sociedade que nem sempre são aparentes ou que aparecem sob o "filtro" do olhar dos que estão instalados no poder, vai mostrar como parcelas excluídas como a população encarcerada no Estado de São Paulo passa a se organizar no sentido de constituir uma lógica no interior do sistema prisional que passa inclusive pelo paradoxo de assimilar o dispositivo da violência-pacificação, ou da 
mediação da fala, de negociações como forma de introduzir mudanças nas relações dentro de um ambiente de repressão e privação de liberdade.

\begin{abstract}
We bring here a number of concerns in this essay on the topic of violence and ways of interpreting it in contemporary society. Searching in this essay articulate global, national and local questions; to what social scientists today, particularly in the analysis of health practices, understood as an expert system has responded to requests that involve a contemporary structural violence whose purpose is the production of what is being called "social suffering".
\end{abstract}

KEYWORDS: Violence, Contemporary Society, Public Health, Social Suffering

\title{
REFERÊNCIAS BIBLIOGRÁFICAS
}

ADORNO, R.C.F., CASTRO, A.L. O exercício da sensibilidade: pesquisa qualitativa e a saúde como qualidade. Saúde e Sociedade, v. 3, n. 2, São Paulo, 1994.

ADORNO, S. Editorial Especial. Saúde e Sociedade, v. 17, n. 3, p 7-8, São Paulo, 2008.

ARENDT, H. A vida do espírito: o pensar, o querer, o julgar. Rio de Janeiro: Civilização Brasileira, 2008.

BECK, U.; GIDDENS, A.;LASCH, S. Modernização reflexiva: política, tradição e estética na ordem moderna. São Paulo: Editora da UNESP, 1997.

BIONDI, K. Junto e misturado: uma etnografia do PCC. São Paulo: Terceiro Nome/FAPESP, 2010.

CALDEIRA, T.P.R. Cidades de muros: crime, segregação e cidadania em São Paulo. São Paulo: EDUSP/Editora 34, 2000.

DAS,V.; KLEINMAN, A.; RAMPHELE, M.; REYNOLDS, P. Violence and subjectivity. Berkeley, Los Angeles and London. University of California Press, 2000. 
DAS, V.; POOLE, D. El estado y sus márgenes. Etnografias comparadas. Cuadernos de Antropologia Social, 27, pp.19-52, 2008.

DONNANGELO, C.; PEREIRA, L. Saúde e Sociedade. São Paulo: Livraria Duas Cidades, 1976.

FASSIN, D. Les figures urbaines de la santé publique: enquete sur des expériences locales. Paris: Éditions La Découverte, 1998.

FASSIN,D. Souffrir pour le social, gouverner par l'écoute: une configuration sémantique de l'action publique. Politix, 19 (73), 2006, p.137-57.

GIDDENS, A. As conseqüências da modernidade. São Paulo: Editora da Universidade Estadual Paulista, 1991.

. A transformação da intimidade: sexualidade, amor e erotismo nas sociedades modernas. São Paulo: Editora da Universidade Estadual Paulista, 1993

.Para além da esquerda e da direita. São Paulo: Editora da Unesp, 1996.

HARVEY, D. A condição pós-moderna. São Paulo: Loyola, 1993.

HOBSBAWM,E. A era dos extremos. Rio de Janeiro: Paz e Terra, 1994.

ILLICH,I. A expropriação da saúde. Nêmesis da Medicina. Rio de Janeiro: Editora Nova Fronteira, 1975.

MENDONÇA, R.T. et al. Medicalização de mulheres idosas e interação com consumo de calmantes. Saúde e Sociedade, Jun 2008, v. 17, n. 2, p. 95-106.

MISSE, M. Crime e violência no Brasil Contemporâneo. Rio de Janeiro: Editora Lumen Juris, 2006. 
NJAINE, K.; MINAYO, M.C. A violência na mídia como tema da área da saúde pública: revisão da literatura. Ciência \& Saúde Coletiva, v. 9, n. 1, p. 201-11, Rio de Janeiro, 2004.

OLIVEIRA, L. Os excluídos existem? Notas sobre a elaboração de um novo conceito. Revista Brasileira de Ciências Sociais, n.33, 1997.

RABINOW, P. Antropologia da razão. Rio de Janeiro: Relume-Dumará, 1999.

SARTI, C. Corpo, violência e saúde: a produção da vítima. Sexualidad, Salud y Sociedad. Revista Latinoamericana, n. 1, p. 89-103, 2009.

SENNET, R. A corrosão do caráter: conseqüências pessoais do trabalho no novo capitalismo. Rio de Janeiro: Record, 1999.

. A cultura do novo capitalismo, $2^{\mathrm{a}}$. Ed. Rio de Janeiro: Record, 2008.

SINGER, P.; CAMPOS, O.; OLIVEIRA, E.M. Prevenir e curar: o controle social através dos serviços de saúde. Rio de Janeiro: Forense-Universitária, 1978.

SUS 20 Anos. A Saúde do tamanho do Brasil. Carta de Mobilização. Acesso em 10/7/2010. http://conselho.saude.gov.br/ultimas_noticias/2008/Carta20anosdoSUS.pdf. WACQUANT, L. As prisões da miséria. Rio de Janeiro: Jorge Zahar Editores, 2001. ZALUAR, A. Do dinheiro e dos homens no tráfico de drogas. In: WESTPHAL,M.F. \& BYDLOWSKI,C.R. (ed.) Violência e juventude . São Paulo, Editora Hucitec, 2010. 